\title{
The concept of intelligence
}

\author{
Michael Hand* \\ Institute of Education, University of London, UK
}

\begin{abstract}
Analyses of the ordinary concept of intelligence are few and far between in philosophical literature. Such analyses as there have been in recent years are heavily influenced by Ryle's suggestion that to act intelligently is to act well or competently in a particular domain. Here I show that there are serious problems with Ryle's account and try to offer a more adequate analysis. I argue that to be intelligent is to have an aptitude for theory-intensive activities. I go on to explain why I think the ordinary concept of intelligence is a useful one for those professionally involved in the practice of education.
\end{abstract}

\section{Introduction}

Let me begin by drawing a basic distinction between ordinary and technical senses of words. By the ordinary sense of a word I mean the sense we learned at our mother's knee, the sense intended and understood by competent English speakers using the word in everyday contexts. By a technical sense I mean a deliberate variation on the ordinary sense introduced to serve a particular theoretical or political purpose.

Now it is not, I hope, controversial to suggest that when psychologists offer definitions of the word 'intelligence', they are normally to be understood as stipulating technical senses rather than attempting to describe the ordinary sense. Certainly the various definitions they have advanced over the last hundred years or so do not fare well as accounts of the criteria governing ordinary usage. Consider, for example, such well-known definitions as 'what the tests of intelligence test' (Boring, 1923, p. 35), 'innate, general, cognitive ability' (Burt, 1955, p. 187) and 'the ability to solve problems or to create products that are valued within one or more cultural settings' (Gardner, 1999, p. 33). That none of these formulae captures the ordinary meaning of 'intelligence' is shown by the fact that they respectively render incoherent the views that IQ tests are not valid measures of intelligence, that differences in intelligence are at least partly attributable to differences in upbringing, and that a person need not be intelligent in order to contribute something valuable to society. Far from being incoherent, these views are both readily intelligible and

\footnotetext{
*Institute of Education, University of London, 20 Bedford Way, London WCIH OAH, UK. Email: m.hand@ioe.ac.uk
} 
widely held. The most natural explanation for the discrepancy between psychologists' definitions and ordinary usage is that psychologists have traditionally been less interested in clarifying the concept of intelligence than in adapting it to their theoretical purposes.

It would therefore be a mistake to infer from the proliferation of psychologists' definitions of 'intelligence' that there is something peculiarly difficult about saying what the word means. That a word has acquired many technical senses does not entail, or even suggest, that its ordinary sense is somehow elusive. It may be elusive, but we cannot assume that it is on the grounds that psychologists have failed to converge on it. There is no reason why they should have converged on something they have made no serious effort to find.

Nor does it follow from psychologists' lack of interest in the everyday concept of intelligence that it is not worth investigating. Again, it is possible that the concept is one we do not much need, perhaps because it is too blunt an instrument for the purposes to which it is usually put, or because it is predicated on an erroneous 'folk psychology'; but we shall not know this until we have subjected it to scrutiny. And, as J. L. Austin pointed out long ago, there are good reasons of a general kind for supposing that the concepts embedded in ordinary language will turn out to be practically useful:

... our common stock of words embodies all the distinctions men have found worth drawing, and the connexions they have found worth marking, in the lifetimes of many generations: these surely are likely to be more numerous, more sound, since they have stood up to the long test of the survival of the fittest, and more subtle, at least in all ordinary and reasonably practical matters, than any that you or I are likely to think up in our arm-chairs of an afternoon. (Austin, 1956, p.182)

My aim in this article, then, is to answer two questions. First, is there a more or less stable and coherent concept marked by the word 'intelligence' as it is ordinarily used by English speakers? And second, if there is such a concept, is it a useful one?

\section{I.}

Before tackling these questions directly, it is worth taking a brief look at previous attempts to clarify the ordinary concept of intelligence. The first thing to note about such attempts is their scarcity. Those with a professional interest in the logical geography of everyday concepts have had remarkably little to say on the subject of intelligence. As John White remarks, 'In philosophical works we can find discussions of consciousness, perception and sensation, thought, action, memory, emotion and imagination, but rarely anything on intelligence' (White, 2002, p. 78). The second thing to note is that the few philosophers who have discussed intelligence in recent years have been heavily influenced by Gilbert Ryle's treatment of the topic in The concept of mind (1949). Unfortunately, as I shall try to show, the analytical trail blazed by Ryle turns out to be a blind alley.

Ryle's analysis of the concept of intelligence appears in a chapter entitled 'Knowing how and knowing that' (Pp. 26-60). His general thesis in this chapter is well-known and unassailable. It is that mental activity is not to be equated with theoretical activity. Human beings do more things with their minds than build, test and apply theories. In particular, practical activities cannot be broken down into mental acts of planning what to do and physical acts of doing it. When clowns trip and tumble in the circus ring, or chefs slice and 
dice in the kitchen, their physical actions are not typically accompanied by short bursts of planning, reflecting or theorizing. If we are tempted to postulate such concomitant theoretical work, it is because we are in the grip of a dogma that makes us view physical actions as merely physical. The truth is that the tumbling of the clown and the slicing of the chef are themselves mental acts as well as physical ones: no behind-the-scenes theorizing is required to bring minds into the picture. This is not to say that clowns and chefs never stop to reflect on their performances, or take time out to plan new routines or recipes; it is simply to say that the status of their performances as operations of mind does not depend on the occurrence of such reflective episodes. I use my mind whenever I tie my shoelaces, whether I first have to think through the procedure for tying bows or not.

This general thesis seems to me to be incontrovertible. The difficulty comes with Ryle's attempt to analyse the concept of intelligence in terms derived from the thesis. He contends that, just as all human actions, whether theoretical or practical, are operations of mind, so they can all be performed either intelligently or stupidly. To do something intelligently is to do it well or competently; to do something stupidly is to do it badly or incompetently. An intelligent person is therefore one who is capable of giving competent performances in a specified sphere of activity. Ryle puts it thus:

\begin{abstract}
The boxer, the surgeon, the poet and the salesman apply their special criteria in the performance of their special tasks, for they are trying to get things right; and they are appraised as clever, skilful, inspired or shrewd not for the ways in which they consider, if they consider at all, prescriptions for conducting their special performances, but for the ways in which they conduct those performances themselves. Whether or not the boxer plans his moves before executing them, his cleverness at boxing is decided in the light of how he fights. If he is a Hamlet of the ring, he will be condemned as an inferior fighter, though perhaps a brilliant theorist or critic. Cleverness at fighting is exhibited in the giving and parrying of blows, not in the acceptance or rejection of propositions about blows. (Ryle, I949, p. 48)
\end{abstract}

For Ryle, then, there are as many kinds of intelligence as there are spheres of human activity, and one has or lacks a particular kind of intelligence to the degree that one has mastered or failed to master the activity in question. '

Unfortunately, the equation of intelligence with competence will not do. The most obvious difficulty is that, whereas it is always appropriate to ask of a person described as competent what she is competent at, it is quite out of place to ask of a person described as intelligent what she is intelligent at. There is something very odd about Ryle's talk of cleverness at boxing. To be clever at all, one is inclined to say, is to be clever across the board. Competences are properties of persons qua clowns, chefs and boxers; intelligence or cleverness is a property of persons qua persons.

Another difficulty is that it is neither a sufficient nor a necessary condition of a performance exhibiting intelligence that it is competent. Competence is not sufficient for intelligence because, at the very least, we should need to know how quickly or easily the competence in question was acquired. Certain competences acquired with unusual speed and little need of instruction are indeed indicators of intelligence; the same competences acquired with great difficulty and following an abnormally long period of instruction certainly are not. That competence is not even necessary for intelligence is shown by the fact that we routinely make judgments about people's intelligence on the strength of their 
earliest efforts to master an activity, long before their performances qualify as competent. A child's attempts to get to grips with calculus may exhibit extraordinary intelligence even if she cannot yet be said to have properly understood it.

A third difficulty with equating intelligence with competence is the consequences it has for the concept of stupidity. If an intelligent person is one who possesses a particular competence, it follows that a stupid person is one who lacks that competence. One is stupid merely by virtue of being a novice. But this plainly runs counter to what we ordinarily mean by stupidity. My not knowing how to play chess does not make me a stupid person, nor even a stupid chess-player; and from the fact that a person is stupid we cannot infer that she lacks the ability to play chess (though, if she has the ability, we can perhaps surmise that it took her longer than most to acquire it).

There are, then, serious problems with Ryle's account of the concept of intelligence. Notwithstanding these problems, it appears to have been adopted more or less wholesale by a number of contemporary philosophers. Thus, for example, Christopher Winch argues that there is no 'single mental property of intelligence', but rather a variety of species of intelligent behaviour (Winch, 1990, p. 7). People are intelligent or stupid in some domain, and performances in a domain qualify as intelligent when they are 'highly apt' or 'particularly well-executed' (p. 7). In support of his argument, Winch offers the following observations about ordinary usage of the word 'intelligence':

We have no difficulty with such expressions as 'He is an intelligent footballer' or 'She handled that parent in an intelligent manner', which suggest a disposition of the footballer or the head teacher to behave in certain ways highly appropriate to the activities in which they are engaging... Where 'intelligence' is used, it can usually be taken as a paraphrase for 'intelligent F' (where 'F' is a term standing for some kind of human activity). (Winch, 1990, p. 7)

As a description of ordinary usage, this is spectacularly wide of the mark. It is simply not true that 'is intelligent' can usually be construed as an abbreviation of 'is intelligent at suchand-such an activity'. When I describe my daughter, my pupil or the hero of my novel as intelligent, I need not, and normally do not, have a particular activity or domain of action in mind. If you were to ask me to identify such an activity, I should be inclined to think that you had misunderstood me. And while it is true that we have no difficulty with the expression 'he is an intelligent footballer', the expression is certainly not equivalent to 'he is a competent footballer'. In fact there are two natural interpretations of this expression. On the first, knowing that someone is an intelligent footballer tells us no more about how he plays football than knowing that he is a bald footballer or a Christian footballer. To borrow a technical distinction from Geach (1956), the adjective 'intelligent' in the statement 'he is an intelligent footballer' may be predicative rather than attributive, which is to say that the statement can be split up, without change of meaning, into the separate statements 'he is a footballer' and 'he is intelligent'. On the second interpretation, to assert that someone is an intelligent footballer is to assert that he plays football intelligently, which is analogous to asserting that he plays football aggressively, generously or courageously. It is, in other words, to remark on how a person's football playing is influenced by one of his general qualities of mind. In neither interpretation do we find support for the idea that an intelligent footballer is just a competent one, or that there is a species of intelligence specific to the activity of football. 
Another contemporary philosopher who ties intelligence closely to competence is John White. White is aware of some of the problems with Ryle's account identified above, but the unpromising measure by which he tries to solve them is to suggest that there are three related but distinct concepts marked by the word 'intelligence' in the English language:

(i) Intelligence as the innate capacity to acquire specific intelligent abilities or capacities. Its opposite is non-intelligence.

(ii) Intelligence in an area as a specific, learned capacity (to speak, forage for food, swim, drive, etc). Its opposite is the non-possession of this capacity.

(iii) Intelligence as the realization, the successful application, of a specific capacity in a particular instance. Its opposite, stupidity or unintelligence, is a failure to apply this acquired capacity. (White, 2002, p. 86)

Thus White holds on to the central Rylean idea that a person is said to be intelligent when she possesses a particular competence, but supplements it with the ideas that a person is also said to be intelligent by virtue of her innate capacity to acquire competences, and when one of her acquired competences is successfully exercised. The first of these supplementary ideas is an attempt to account for ascriptions of intelligence to persons qua persons: the innate capacity to acquire competences is a general property of the human mind. The second is an attempt to solve the problem of stupidity: one is not now stupid because one lacks a particular competence, but because one fails to exercise a competence one possesses at the appropriate time.

These amendments, however, merely paper over the cracks in Ryle's account. Although White supplies us with a sense of 'intelligence' that is not domain-specific, it is not a sense that allows us to distinguish between intelligent and unintelligent people. Since all people have the innate capacity to acquire competences, all people qualify as intelligent in this sense. We are still precluded from making the perfectly ordinary observation that Dawn is an intelligent person and Tim is not. And the suggestion that stupidity consists in failure to exercise competence is in some ways even less satisfactory than the suggestion that it consists in lack of competence. For stupidity on this account is not only domain-specific but also occasion-specific. I am being stupid when I perform badly in a domain in which I am capable of performing well; but my stupidity lasts only as long as my bad performance. Stupidity 'is not an enduring feature of our personality, but a one-off or occasional failure - through tiredness, anxiety, panic or whatever-to activate the knowhow we possess' (p. 86). But plainly this leaves a great many ordinary uses of the word 'stupid' out of the picture. While it accounts well enough for talk of 'stupid decisions' and 'moments of stupidity', it hardly begins to account for talk of 'stupid people' and 'congenital stupidity'. White's conclusion that this latter kind of talk is 'logically awry' (p. 86) seems to me to constitute a reductio ad absurdum of his position. An account of the concept of stupidity that cannot accommodate such familiar, everyday uses is selfevidently incorrect.

Existing philosophical treatments of intelligence, then, turn out to be of little help to us. To make any progress here we shall need to retreat from Ryle's blind alley and broach the analytical task afresh. 
II.

Let us begin with some preliminaries. First, intelligence is a quality of mind possessed to different degrees by different people. We say of some people that they are highly intelligent, of others that they are moderately intelligent, and of still others that they are not intelligent at all. In this respect the quality of mind designated by the term 'intelligence' resembles such qualities of mind as ambition, generosity and sensitivity. People are more or less intelligent just as they are more or less ambitious, generous and sensitive.

Second, we assess people's intelligence in the same way as we assess their other qualities of mind: by observing their behaviour in appropriate contexts. Certain kinds of behaviour in certain kinds of context prompt us to describe people as intelligent or unintelligent, just as other kinds of behaviour prompt us to describe them as ambitious or unambitious, generous or mean, sensitive or insensitive. Such assessments are not infallible: the behaviour observed on a particular occasion may be untypical, or designed deliberately to mislead. But where a person consistently displays the behaviour associated with a particular quality of mind over a significant period of time, and there is no reason to suppose that she is engaged in an elaborate deception, we reasonably conclude that she possesses the quality of mind in question.

Third, in ascribing to people such qualities of mind as intelligence, ambition and generosity, one is not committing oneself to any view about their biological or environmental origin. It remains an open question whether intelligence is a product of nature or nurture, or whether there is any meaningful way of quantifying the respective contributions of the two. Attempts to write an answer to this question into the concept of intelligence itself are wholly misguided. Intelligence might be innate or fixed, but it is not innate or fixed by definition; and the position one happens to take in the nature-nurture debate has no bearing at all on one's ability to distinguish intelligent people from unintelligent ones.

With these preliminaries in mind, I should like to advance my first substantive claim about the concept of intelligence: the quality of mind picked out by the term 'intelligence' is a species of aptitude. Aptitudes stand in an important logical relation to competences but are nevertheless sharply distinct from them. Grasping this relation and this distinction is the key to understanding the logic of everyday discourse about intelligence.

To possess a competence is to have reached a certain level of achievement in some activity or practice. A competent practitioner is one who is capable of giving good or correct performances. Competence is therefore the sort of thing that can, in principle at least, be assessed by means of tests, examinations, auditions or inspections. If people are able to give good or correct performances on demand, it is reasonable to infer that they possess the associated competences.

To have an aptitude, on the other hand, is not necessarily to be capable of giving good or correct performances. A person may have an aptitude for something without yet being able to do it well. Ascriptions of aptitudes are not claims about the possession of competences, but claims about the ease with which competences are acquired. Tim is said to have an aptitude (or talent, or flair) for football when he finds it relatively easy to acquire the various skills and dispositions required to play football well; and this is usually evident long before Tim is playing football at a level appropriately described as competent. The 
fact that it is easier for people with an aptitude for something to become competent at it does not imply that competence is unattainable by those who lack aptitude. Some activities, perhaps, are so complex or sophisticated that only those with relevant aptitudes can hope to progress to the level of competence; but plenty of others are masterable by more or less anyone. The crucial point about my aptitudes is not that they determine the range of competences available to me, but that they determine how difficult I will find it to acquire the competences I wish to possess.

Some aptitudes resemble competences in being tied to specific activities. One may have an aptitude for clowning, cooking or boxing just as one may be competent at these things. But other aptitudes are more general in nature, tied not to specific activities but to clusters of related activities. Consider, for example, the aptitudes we ascribe to people when we identify them as being musical or sporty. Musical people are those to whom a range of musical competences come relatively easily, or would come easily if they set their minds to acquiring them. Competence on the piano obviously does not imply competence on the flute or the violin; yet some people find that they are able to make rapid progress with any musical instrument they turn their hand to. Such people have a general aptitude for musical activities, as distinct from a specific aptitude for just one. Sporty people, similarly, are those whose talent is not just for football or basketball, but for the whole spectrum of sporting activities.

There is no great mystery about how aptitudes are identified. We find out about people's aptitudes by monitoring their learning in different areas of activity. Activities in which people learn easily and progress rapidly are those for which they have an aptitude; activities in which their learning is laboured and their progress slow are those for which they lack aptitude. One context in which people's learning is routinely monitored in precisely the way required to identify their aptitudes is, of course, the school. Teachers observe pupils as they engage in learning tasks, assess their progress at regular intervals, and talk to them about what they find easy or difficult. Such observations, assessments and conversations constitute a reliable basis for the diagnosis of aptitudes and inaptitudes.

There is, however, something very odd about the idea that aptitudes might be identified by means of one-off tests or examinations. What tests and examinations can supply are snapshots of current levels of competence in an activity; what they obviously cannot supply is information about the ease or difficulty with which those levels of competence were acquired. What matters, from the point of view of aptitude, is not what a person can currently do, but whether the process by which she learned how to do it was an arduous one. This can only be assessed by monitoring a person's learning over a period of time. If this is right, and if intelligence is a species of aptitude, it follows that one thing 'intelligence tests' cannot possibly measure is intelligence.

My second substantive claim about the concept of intelligence is this: the quality of mind picked out by the term 'intelligence' is an aptitude for theorizing. By 'theorizing' I mean producing, evaluating and applying theories; and by 'theories' I mean the wide variety of cognitive constructions by which human beings plan, govern and justify their actions and organize, narrate and explain their experiences. So construed, the class of theories includes such intellectual products as the following: 
plans, plots, strategies, schemes, programmes;

procedures, protocols, methods, algorithms;

policies, principles, ideals, rules, norms;

justifications, reasons, arguments, rationales, rationalizations, excuses;

accounts, descriptions, interpretations, analyses, taxonomies;

narratives, histories, biographies, stories, anecdotes;

explanations, hypotheses, theorems, proofs, syllogisms, equations.

It will be clear that theorizing does not qualify as an activity in the sense we have been using that term: there is no unified practice of theorizing, nor can one be competent at theorizing per se. Rather, theorizing is embedded, in different forms and with different purposes, in a great many of the activities in which human beings engage. Indeed, it is difficult to think of an activity that does not involve theoretical work of one sort or another. But while it may be true that all activities make some theoretical demands on practitioners, the weight of these demands varies considerably. Some activities, perhaps certain sports and certain routinized industrial and commercial practices, require only occasional and low-level theory-production. An aptitude for theorizing confers little or no advantage on those trying to master such activities. Other activities, like academic disciplines, games of strategy and professions based on reflective practice, have theorizing at their heart. And while an aptitude for theorizing is not a necessary condition of acquiring competence in these activities, those who have it are undoubtedly at an advantage.

Intelligence, then, is an aptitude of the kind described above as general rather than specific. To be intelligent is to have a general aptitude for theory-intensive activities. (I use the phrase 'theory-intensive activities' in preference to 'theoretical activities' because, following Aristotle, I take the latter to refer specifically to those activities concerned with the pursuit of truth. The class of theory-intensive activities includes but is not exhausted by the class of theoretical activities: it also includes those practical activities in which moral deliberation or technical reasoning is to the fore.) Just as musical and sporty people have talents for the spectra of musical and sporting activities respectively, so intelligent people have a talent for the spectrum of activities centrally concerned with the production, evaluation and application of theories.

In the foregoing analysis I have deliberately avoided two terms that often feature prominently in discussions of intelligence: 'ability' and 'thinking'. These are, of course, perfectly ordinary and respectable English words; but it seems to me that their use in this area tends to obscure rather than illuminate important distinctions. The distinction obscured by 'ability' is that between an aptitude and a competence. To describe a pupil as having 'high ability' in some area of the curriculum is ambiguous between asserting that she has reached a high level of competence or achievement in that area and asserting that she has a particular aptitude for it. Often the two go together and the ambiguity does not much matter; but they do not always go together (which is why it makes sense to talk of 'able underachievers'), and in any case, as I have tried to show, the distinction between the two is crucial for a correct understanding of the concept of intelligence.

The distinction blurred by the word 'thinking' is the one drawn so vividly by Ryle in The concept of mind, between theorizing and other kinds of mental activity. In much 
educational discourse, and particularly in references to 'thinking skills' and 'teaching children to think', thinking is synonymous with theorizing. But the term 'thinking' is also used much more widely, to include all of the many and varied things people do with their minds. Even this formulation might be thought too narrow, on the grounds that it implies too much agency: what I am thinking about at any given moment arguably includes the things of which I am passively aware, or the idle thoughts passing unbidden through my head, as well as anything to which I am giving active attention. Be that as it may, Ryle's clown and chef, in the midst of their tumbling and dicing, are unquestionably thinking about what they are doing without thereby theorizing about it. Thinking here takes the form of attending to the task in hand, of exercising control over one's movements, of monitoring one's own performance and being ready to deal with problems as they arise. None of this has anything to do with building or applying theories. Like 'ability', then, 'thinking' is too ambiguous a term to be of much help to us in our efforts to clarify the concept of intelligence.

III.

Of the two questions posed at the beginning of this article, I have answered the first in the affirmative: there is a stable and coherent concept marked by the word 'intelligence' as it is ordinarily used by English speakers. To be intelligent is to have an aptitude for theorizing. I turn now to the second question: is this concept a useful one?

One plausible condition of the usefulness of a concept is that it should have application. The idea of an aptitude for theorizing may be a coherent one, but it remains a further question whether any human being actually possesses this quality of mind. Perhaps we live in a world in which people have specific aptitudes for such theory-intensive activities as mathematics, chess and medicine, but no-one has a general aptitude for theory-intensive activities per se. If so, we shall be obliged to classify 'intelligence' as a term with a connotation but no denotation.

The first thing to say here is that, while there clearly are people with specific aptitudes for just one or two theory-intensive activities, this fact in itself does not count against there being people with a general aptitude for all of them. It will not do to point to people with a talent for history but an inaptitude for mathematics, or a flair for accountancy but an incapacity for engineering, and claim thus to have discredited the idea of intelligence. What these cases show is that the categories of high, medium and low intelligence do not have universal application: some people have configurations of aptitudes that make it impossible, or artificial, to place them on this scale. But from the fact that not everyone can be said to have a general aptitude or inaptitude for theorizing, it hardly follows that no-one can.

It is worth noting that intelligence does not differ in this regard from other general qualities of mind. There are people who have a notable aptitude for one sport but who progress no more quickly than anyone else in their attempts to master others. Should we say that these people are or are not sporty? Both descriptions are misleading. Or, to move from aptitudes to virtues, how should we describe the character of soldiers who fight bravely on the battlefield but shrink from commitment and responsibility in their personal 
lives? Do they possess or lack the virtue of courage? And what of animal lovers deeply moved by the pain of animals but untouched by the suffering of their fellow human beings? Should we ascribe to them the virtue of compassion? There are no correct answers to these questions: in each case we are dealing with sets of personal characteristics that are not readily classifiable under general aptitude or virtue terms. This does not mean, however, that general aptitude and virtue terms are redundant, for not all people are like the ones in these examples. Many people are straightforwardly sporty, courageous or compassionate, and many others straightforwardly lack these qualities. It is not a condition of the usefulness of general quality of mind concepts that their range of application is universal.

Accepting, then, that not everyone is well-described as having either an aptitude or an inaptitude for theory-intensive activities, what grounds can be given for holding that there are at least some people to whom these descriptions are applicable? Here I can only appeal to everyday experience, and in particular to everyday experience in schools. To have attended school, as either pupil or teacher, is to have observed at close quarters large numbers of pupils attempting to master a wide range of activities. What anyone who has made such observations can hardly fail to notice is that, in addition to the pupils who display specific talents for one or two activities, there are also pupils who display talents of a more general kind, talents for groups of activities with salient features in common. These are the pupils who take easily to musical activities, or sporting activities, or theory-intensive activities, across the board. So marked and so prevalent are these general aptitudes in schools that it is not uncommon to find them forming the bases of pupils' friendship groups: the 'jocks' make up one gang, the 'brains' another. Ascriptions of intelligence are therefore at least as securely grounded in everyday experience as ascriptions of any other general quality of mind.

Our question, however, is not just whether the concept of intelligence has application, but whether it is useful. The fact that some people are accurately described as having or lacking intelligence does not show that so describing them serves any practical purpose. Are there, then, respectable practical pursuits in which accurate assessments of people's intelligence are both possible and useful?

I contend that education is just such a pursuit. I have already explained why teachers are in a good position to assess aptitudes: they observe, test and converse with pupils as they engage in a variety of learning activities over a significant period of time. What still needs to be shown is that assessing aptitudes assists teachers in their work. How, in practice, does it help teachers to know whether their pupils are of high, moderate or low intelligence, or have configurations of aptitudes that resist classification on this scale? I suggest that it helps them in at least two ways.

First, knowing something about the intelligence of their pupils helps teachers to plan and pace their teaching. When the teacher of a theory-intensive activity designs a programme of study for a class or group, she has to make judgments about how long it will take the pupils to grasp each new concept, explanation or theoretical skill, and thus how soon they will be ready to move on. These judgments are of course provisional: every teacher knows that she must be ready to change her plans in the light of unanticipated responses, distractions and obstacles to learning. But this does not detract from the 
importance of thorough planning informed by realistic expectations about how quickly pupils will progress. To know that some or all of the pupils in a group have either an aptitude or an inaptitude for theoretical work is to be in possession of information highly pertinent to this task. More intelligent pupils can be expected to move quite rapidly through programmes of theoretical study; less intelligent pupils are likely to progress much more slowly. And if the teacher is aware that the pupils in her class have disparate levels of intelligence, she knows that her programme of study needs to be sophisticated and flexible enough to allow for the introduction of new concepts, explanations and skills to different pupils at different times.

Second, assessing pupils' intelligence establishes expectations about their normal rate of learning in theoretical areas, which in turn facilitates the identification of abnormal successes and failures. When a highly intelligent pupil appears unable to grasp a new concept, or a pupil of low intelligence appears to master a new theoretical skill very quickly, something is going on that stands in need of investigation. In the former case, the teacher must consider at least the following possibilities: (i) that her explanation of the new concept was in some way deficient or unclear; (ii) that the pupil is distracted, perhaps by problems at home or in the playground; (iii) that the pupil, though intelligent enough, is simply not interested in the topic; and (iv) that her assessment of the pupil as highly intelligent stands in need of revision. In the latter case, the possibilities she needs to consider include: (i) that she has found a particularly effective way of teaching the skill in question; (ii) that the pupil's success is only apparent and the work exhibiting the new skill was copied from a friend or completed by a family member; (iii) that the pupil, despite having an inaptitude for other theory-intensive activities, nevertheless has an aptitude for this one; and, again, (iv) that the pupil's level of intelligence has been misdiagnosed. It matters that teachers investigate abnormal successes and failures because it matters which of the various possible explanations for them are right; but such abnormalities can only come to light against a background of expectations about individual pupils' normal rates of learning.

I conclude that the word 'intelligence', as it is ordinarily used by English speakers, marks a concept that is stable, coherent, readily understandable and educationally useful. To be intelligent is to have an aptitude for theory-intensive activities; and to know whether people are intelligent is to be in a better position to educate them well. That the ordinary concept of intelligence is straightforward and serviceable does not mean that the multitude of technical definitions devised for the theoretical purposes of psychologists are without value; but it does suggest that we need be neither seduced by the scientific lustre of those definitions nor unsettled by their bewildering variety.

\section{Notes}

I. Ryle revisited the concept of intelligence some 25 years later in a short paper presented to the Philosophy of Education Society of Great Britain (Ryle, 1974). Here he does not attempt to say what the word 'intelligence' means, but contents himself with some general remarks about the multiplicity of species of intelligence and the consequent unanswerability of 'the over-generic question "How intelligent is he?"' (p. 53). Nothing in the paper either contradicts or usefully adds to his account in The concept of mind. 


\section{Notes on contributor}

Michael Hand is Senior Lecturer in Education at the Institute of Education, University of London.

\section{References}

Austin, J. L. (1979) A plea for excuses, in: J. L. Austin, Philosophical papers (Oxford, Oxford University Press) (original work published 1956).

Boring, E. G. (1923) Intelligence as the tests test it, New Republic 35, 35-37.

Burt, C. (1955) The evidence for the concept of intelligence, in: S. Wiseman (Ed.) Intelligence and ability (Harmondsworth, Penguin).

Gardner, H. (1999) Intelligence reframed (New York, Basic Books).

Geach, P. T. (1967) Good and evil, in: P. Foot (Ed.) Theories of ethics (Oxford, Oxford University Press) (original work published 1956).

Ryle, G. (1990) The concept of mind (Harmondsworth, Penguin) (original work published 1949).

Ryle, G. (1974) Intelligence and the logic of the nature-nurture issue: reply to J. P. White, Proceedings of the Philosophy of Education Society of Great Britain, 8(I), 52-60.

White, J. (2002) The child's mind (London, RoutledgeFalmer).

Winch, C. (1990) Language, ability and educational achievement (London, Routledge). 